\title{
Analisis Kinerja Pembangunan Provinsi Nusa Tenggara Barat Dalam Aspek Kesejahteraan, Ketimpangan, Pembangunan Manusia, Pendidikan Dan Kesempatan Kerja
}

\author{
Wahidin, Sahri, Putu Karismawan, M.Firmansyah.
}

Universitas Mataram

ARTICLE INFO
Received : 10 Januari 2018; Accepted: 22 Februari 2018; Published: Maret 2018

Keywords :

Welfare, income inequality, human development, education participation, labor force participation.

ABSTRACT : This study aims to: examine the effect of Government Expenditures The scope of this study evaluates the development performance of the province of Nusa Tenggara Barat with the objective to mengeatahui economic prosperity of the population, income inequality among the population, human development progress, education participation of the population, and labor force participation. Research variables: per capita income (PDRB per capita), number of households, household income, ie harapa life rate, literacy rate, school participation rate (APS), rough participation rate (APK), and net enrollment rate (APM), the population of the working labor force, the working age population. Data of research variables using time series data (time series) last five years. Data analysis using descriptive statistical analysis. Result of research: level of economic prosperity of society increase from year to year. Despite the increase but the economic welfare of NTB population is still below the economic welfare level of the population of the provinces in the West Indonesia region. The inequality of income distribution between urban and rural population is at a moderate level of inequality. The growth rate of NTB's HDI is highest in Indonesia, but still ranks 30 out of 34 provinces in Indonesia. The education participation rate of NTB population is above ninety percent. The labor force participation rate of NTB population has increased and has reached the figure of seventy percent.

Kata Kunci :

kesejahteraan, ketimpangan pendapatan, pembangunan manusia, partisipasi pendidikan, partisipasi angkatan kerja.

ABSTRAK : Penelitian ini bertujuan mengevaluasi kinerja pembangunan propinsi Nusa Tenggara Barat dengan tujuan untuk mengeatahui kesejahteraan ekonomi penduduk, ketimpangan pendapatan antar penduduk, kemajuan pembangunan manusia, partisipasi pendidikan penduduk, dan partisipasi angkatan kerja. Variabel penelitian: pendapatan per kapita (PDRB per kapita), jumlah rumah tangga, pendapatan rumah tangga, yaitu tingkat harapa hidup, tingkat melek huruf, Angka Partisipasi Sekolah (APS), Angka Partisipasi Kasar (APK), serta Angka Partisipasi Murni (APM), penduduk angkatan kerja yang sudah bekerja, penduduk usia kerja. Data variabel penelitian menggunakan data runtut waktu (time series) lima tahun terakhir. Analisis data menggunakan analisis statistik diskriptif. Hasil penelitian: tingkat kesejahteraan ekonomi masyarakat meningkat dari tahun ke tahun. Walaupun meningkat tetapi tingkat kesejahteraan ekonomi penduduk NTB masih berada di bawah tingkat kesejahteraan ekonomi penduduk propinsi-propinsi di wilayah Indonesia Barat. Tingkat ketimpangan distribusi pendapatan antar penduduk di perkotaan dan pedesaan berada pada tingkat ketimpangan sedang. Tingkat pertumbuhan IPM NTB termasuk tertinggi di Indonesia, namun masih menempati posisi 30 dari 34 provinsi di Indonesia. Tingkat partisipasi pendidikan penduduk NTB sudah di atas angka sembilan puluh persen. Tingkat partisipasi angkatan kerja penduduk NTB mengalami peningkatan dan sudah mencapai angka tujuh puluh persen.

Corresponding Author:

Alamat : Program Studi Ekonomi Pembangunan, Fakultas Ekonomi dan Bisnis, Universitas Mataram, Jln. Majapahit No. 62 Mataram.

e-mail: wahidin@gmail.com 


\section{PENDAHULUAN}

\section{Latar Belakang}

Pembangunan merupakan suatu proses menuju kearah yang lebih baik dalam segala aspek kehidupan. Olek karena itu pembangunan harus menciptakan perubahan yang bersifat multidimensional dalam berbagai bidang kehidupan. Hal ini sejalan dengan pandangan Michael P. Todaro yang mengatakan bahwa Development is a multidimentional process involving the reorganization and reorientation of entire economic and social systems (Pembangunan merupakan proses multidimensi yang meliputi perubahan organisasi dan orientasi dari seluruh sistem sosial dan ekonomi).

Pembangunan yang dilaksanakan oleh pemerintah dan pemerintah daerah bertujuan untuk mengurangi disparitas atau ketimpangan pembangunan antar daerah dan antar sub daerah serta antar warga masyarakat (pemerataan dan keadilan), memberdayakan masyarakat dan mengentaskan kemiskinan, menciptakan atau menambah lapangan kerja, meningkatkan pendapatan dan kesejahteraan masyarakat daerah, mempertahankan atau menjaga kelestarian sumber daya alam agar bermanfaat bagi generasi sekarang dan generasi masa datang (berkelanjutan).
Untuk mewujudkan tujuan tersebut di atas, tiap tahun pemerintah daerah meningkatkan Anggaran Pendapatan dan Belanja Daerah (APBD).Disamping belanja pemerintah daerah, pemerintah daerah propinsi NTB mendorong peningkatan investasi dari tahun ke tahun.Demikian pula berbagai kebijakan telah dikeluarkan oleh pemerintah propinsi NTB mulai dari kebijaka fiscal, kebijakan moneter, kebijakan dalam bidang investasi dan kebijakan dalam bidang pembangunan manusia, sosial, pendidikan, dan kesehatan. Kebijakan ini semua ditujukan untuk mempercepat pemangunan di propinsi NTB dalam berbagai aspek.

\section{Perumusan masalah}

Bagaimana kinerja pembangunan pemerintah Propinsi Nusa Tenggara Barat dalam bidang kesejahteraan ekonomi penduduk, distribusi pendapatan antar penduduk, pembangunan manusia, pendidikan masyarakat, dan penyerapan tenaga kerja..

\section{Tujuan dan manfaat penelitian}

Untuk mengetahui hasil pembangunan pemerintah Propinsi Nusa Tenggara Barat dalam bidang kesejahteraan ekonomi penduduk, distribusi pendapatan antar penduduk, pembangunan manusia, pendidikan masyarakat, dan penyerapan tenaga kerja. 


\section{TINJAUAN PUSTAKA}

\section{Pembangunan}

Pembangunan dapat diartikan berbedabeda oleh setiap orang tergantung dari sudut pandang apa yang digunakan oleh orang tersebut. Perbedaan cara pandang mengenai proses pembangunan yang dilakukan akan menyulitkan kepada kita tentang seberapa maju proses pembangunan yang dilakukan di sebuah negara atau daerah (Tri Widodo, 2006).

Dalam pandangan tradisional, pembangunan diartikan sebagai berbagai upaya yang dilakukan untuk meningkatkan pertumbuhan Produk Domestik Bruto (PDB) atau Produk Domestik Regional Bruto (PDRB). Dalam pandangan modern, pembangunan dilihat sebagai upaya pembangunan yang tidak lagi menitikberatkan pada pencapaian pertumbuhan PDB atau PDRB sebagai tujuan akhir, melainkan pengurangan tingkat kemiskinan yang terjadi, penanggulangan ketimpangan pendapatan serta penyediaan lapangan kerja yang mampu menyerap angkatan kerja produktif.

Dari dua definisi pembangunan di atas, proses pembangunan yang dilakukan haruslah memiliki tiga nilai inti dan tiga tujuan pembangunan (Todaro dalam Tri Widodo, 2006). Tiga nilai inti pembangunan adalah: kemampuan untuk memenuhi kebutuhan dasar (sustenance), manusia terhormat (self-esteem), kebebasan (freedom from servitude). Sementara tujuan pembangunan adalah: peningkatan ketersediaan serta perluasan distribusi barang kebutuhan pokok, peningkatan standar hidup, perluasan pilihan ekonomis dan sosial bagi setiap individu.

\section{Pendapatan Per Kapita}

Pendapatan per kapita merupakan indikator yang paling sering digunakan sebagai tolok ukur tingkat kesejahteraan ekonomi penduduk suatu negara.Pendapatan per kapita itu sendiri merupakan indikator kinerja perekonomian secara keseluruhan. Pendapatan per kapita adalah indikator moneter atas setiap kegiatan ekonomi penduduk suatu negara (Lincolin Arsyad, 2010)

\section{Distribusi Pendapatan}

Distribusi pendapatan perorangan merupakan indikator yang paling umum digunakan oleh para ekonom. Indikator sederhana ini menunjukkan hubungan antara individu-individu dengan pendapatan total yang mereka terima.Ukuran umum ketidakmerataan pendapatan adalah perbandingan antara pendapatan yang diterima oleh 40 persen 
4 | Wahidin, Sahri, Putu Karismawan, M.Firmansyah /Analisis Kinerja....

pendduduk terendah dan 20 persen penduduk tertinggi.Perbandingan ini sering digunakan sebagai ukuran derajat ketidakmerataan antara negara maju dan negara miskin (Lincolin Arsyad, 2010).

\section{Indikator Distribusi Pendapatan}

1. Kurva Lorens

Untuk menganalisis distribusi pendapatan perorangan adalah kurva Lorenz yang menggambarkan hubungan antara kelompok-kelompok penduduk dan pangsa pendapatan mereka.Kurva Lorenz menunjukkan hubungan kuantitatif antara persentase penduduk dan persentase pendapatan yang mereka terima.Semakin jauh kurva Lorenz tersebut dari garis diagonal (kemerataan sempurna) maka semakin tinggi pula derajat ketidakmerataan yang ditunjukkan. Semakin tinggi derajat ketidakmerataannya, maka kurva Lorenz tersebut juga akan semakin melengkung dan semakin mendekati sumbu horizontal sebelah bawah.

\section{Koefisien Gini}

Indikator untuk menganalisis distribusi pendapatan perorangan adalah koefisien gini. Seacara matematis rumus koefisien Gini dapat disajikan sebagai berikut:

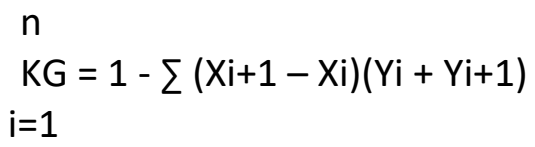

Keterangan:

KG = Angka Koefisien Gini

$X_{i}=$ Proporsi jumlah rumah tangga kumulatif dalam kelas

$\mathrm{fi}=$ Proporsi jumlah rumah tangga dalam kelas $\mathrm{i}$

$Y_{i}=$ Proporsi jumlah pendapatan rumah tangga kumulatif dalam kelas i

Koefisien Gini ini merupakan ukuran ketidakmerataan agregat dan nilainya terletak antara 0 (kemerataan sempurna) sampai 1 (ketidakmerataan sempurna). Kefisien Gini dari negaranegara yang mengalami ketidakmerataan tinggi berkisar antara $0,50-0,70$, ketidakmerataan sedang berkisar antara $0,36-0,49$, dan ketidakmerataan rendah berkisar antara 0,20 - 0,35 (Lincolin Arsyad, 2010)

4. Pembangunan Manusia.

Sejak tahun 1990, United Nations for Development Program (UNDP) mengembangkan sebuah indeks kinerja pembangunan yang kini dikenal sebagai Indeks Pembangunan Manusia atau IPM (Human Development Index).Nilai IPM ini diukur berdasarkan tiga indikator sebagai acuan yaitu tingkat harapa hidup, tingkat melek huruf, dan pendapatan riil per kapita berdasarkan paritas daya beli. Berdasarkan indek IPM ini, negara-negara 
di dunia ini dikelompkkan menjadi tiga yaitu:

a. Kelompok negara dengan tingkat pembangunan manusia yang rendah (low human development), bila memiliki nilai IPM antara 0 sampai 0,50

b. Kelompok negara dengan tingkat pembangunan manusia menengah (medium development), bila memiliki nilai IPM antara 0,50 sampai 0,79.

c. Kelompok negara dengan tingkat pembangunan manusia yang tinggi (high human development) bila memiliki nilai IPM antara 0,79 sampai 1 .

\section{Partisipasi Pendidikan Masyarakat}

Keberhasilan pembangunan suatu wilayah ditentukan oleh sumber daya manusia yang berkualitas. Pendidikan merupakan salah satu cara meningkatkan kualitas SDM tersebut. Oleh karena itu peningkatan mutu pendidikan harus terus diupayakan, dimulai dengan membuka kesempatan seluas-luasnya kepada penduduk untuk mengenyam pendidikan, hingga pada peningkatan kualitas dan kuantitas sarana dan prasarana pendidikan.Untuk mengetahui seberapa banyak penduduk yang memanfaatkan fasilitas pendidikan dapat dilihat dari persentase penduduk menurut partisipasi sekolah. Untuk melihat partisipasi sekolah dalam suatu wilayah biasa dikenal beberapa indikator untuk mengetahuinya, antara lain: Angka Partisipasi Sekolah (APS), Angka Partisipasi Kasar (APK), serta Angka Partisipasi Murni (APM).

\section{Angka Partisipasi Sekolah (APS)}

Angka Partisipasi Sekolah merupakan ukuran daya serap lembaga pendidikan terhadap penduduk usia sekolah. APS merupakan indikator dasar yang digunakan untuk melihat akses penduduk pada fasilitas pendidikan khususnya bagi penduduk usia sekolah. Semakin tinggi Angka Partisipasi Sekolah semakin besar jumlah penduduk yang berkesempatan mengenyam pendidikan.

\section{Angka Partispasi Kasar (APK)}

Angka Partisipasi Kasar (APK), menunjukkkan partisipasi penduduk yang sedang mengenyam pendidikan sesuai dengan jenjang pendidikannya. Angka Partisipasi Kasar (APK) merupakan persentase jumlah penduduk yang sedang bersekolah pada suatu jenjang pendidikan (berapapun usianya) terhadap jumlah penduduk usia sekolah yang sesuai dengan jenjang pendidikan tersebut.

Nilai APK bisa lebih dari 100\%. Hal ini disebabkan karena populasi murid yang bersekolah pada suatu jenjang pendidikan 
mencakup anak berusia di luar batas usia sekolah pada jenjang pendidikan yang bersangkutan.

\section{Angka Partisipasi Murni (APM)}

Angka Partisipasi Murni (APM) adalah persentase jumlah anak pada kelompok usia sekolah tertentu yang sedang bersekolah pada jenjang pendidikan yang sesuai dengan usianya terhadap jumlah seluruh anak pada kelompok usia sekolah yang bersangkutan.Angka Partisipasi Murni (APM) mengukur proporsi anak yang bersekolah tepat waktu.

Bila seluruh anak usia sekolah dapat bersekolah tepat waktu, maka APM akan mencapai nilai 100. APM menunjukkan proporsi siswa yang terlambat atau terlalu cepat bersekolah. Keterbatasan APM adalah kemungkinan adanya under estimate karena adanya siswa diluar kelompok usia yang standar di tingkat pendidikan tertentu.

\section{Tingkat Partisipasi Angkatan Kerja (TPAK)}

Tingkat Partisipasi Angkatan Kerja adalah suatu indikator ketenagakerjaan yang memberikan gambaran tentang penduduk yang aktif secara ekonomi dalam kegiatan sehari-hari merujuk pada suatu waktu dalam periode survei.Indikator yang dapat mengambarkan partisipasi angkatan kerja yaitu:
General Economic Activity Ratio (Rasio Aktifitas Ekonomi Umum).Rasio ini khusus untuk penduduk usia kerja, atau biasa disebut Tingkat Partisipasi Angkatan Kerja (TPAK). TPAK adalah indikator yang biasa digunakan untuk menganalisa partisipasi angkatan kerja.

Rumus:

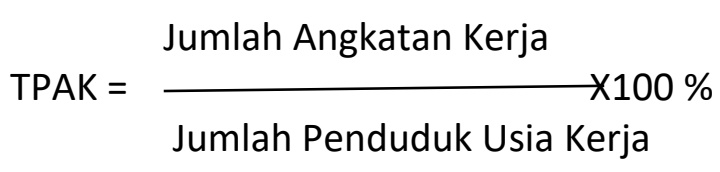

\section{METODE PENELITIAN}

\section{Jenis Penelitian.}

Jenis penelitian ini adalah penelitian evaluasi. Untuk mengevaluasi hasil pembangunan yang dicapai oleh pemerintah propinsi Nusa Tenggara Barat selama kurun waktu lima tahun dalam aspek kesejahteraan ekonomi masyarakat, ketimpangan pendapatan, pembangunan manusia, pendidikan, dan ketenagakerjaan

\section{Jenis dan Sumber Data}

Jenis data yang digunakan adalah data sekunder, yaitu data yang telah dipublikasikan secara resmi oleh instansi pemerintah dan swasta sesuai dengan bidangnya masing-masing. Data yang telah dipublikasikan oleh Badan Pusat Statis (BPS) dan Badan Perencanaan Pembangunan Daerah (Bappeda) propinsi Nusa Tenggara Barat (NTB), Dinas 
Ketenagaakerjaan propinsi NTB, Dinas Pendidikan dan Olah Raga propinsi NTB.

\section{Metode pengumpulan Data}

Metode pengumpulan data yang digunakan adalah metode Studi Kepustakaan, yaitu teknik pengumpulan data dengan jalan membaca dan mencatat data-data yang diperoleh dari instansi-instansi terkait dan dari bahanbahan yang berhubungan dengan masalah yang diteliti (Nazir, 2011: 127). Instansi yang terkait yaitu Badan Pusat Statistik Propinsi (BPS) Popinsi Nusa Tenggara Barat dan Badan Perencanaan Pembangunan Daerah (Bappeda) propinsi Nusa Tenggara Barat, Dinas Ketenagaakerjaan propinsi NTB, Dinas Pendidikan dan Olah Raga propinsi NTB.

\section{Metode Analisis Data}

1. Untuk mengevaluasi kesejahteraan ekonomi masyarakat digunakan pendapatan perkapita dengan formulasi rumus ( $\mathrm{Hg}$. Suseno Triyanto Widodo, 1990)

Ykap $\mathrm{t}=\mathrm{PDRBt} / \mathrm{Pt}$

Dimana :

Ykap,t = Pendapatan perkapita pada tahun $\mathrm{t}$

PDRBt $=$ Produk Domestik Regional Bruto tahun $\mathrm{t}$

Pt = Jumlah penduduk tahun $\mathrm{t}$
2. Untuk mengevaluasi ketimpangan pendapatan antar penduduk digunakan Gini Koefisien dengan rumus (Lincolin Arsyad, 2010):

$K G=1-\sum\left(X_{i+1}-X_{i}\right)\left(Y_{i}+Y_{i+1}\right)$ atau $K G$ $=1-f_{i}\left(Y_{i+1}+Y_{i}\right)$

Dimana :

KG = Angka Koefisien Gini

$X_{i}=$ proporsi jumlah rumah tangga kumulatif dalam kelas i

$\mathrm{fi}=$ proporsi jumlah rumah tangga dalam kelas i

$\mathrm{Yi}=$ proporsi jumlah pendapatan rumah tangga kumulatif dalam kelas i

3. Untuk mengevaluasi pembangunan manusia digunakan Indeks Pembangununan Manusia (IPM) yang diukur berdasarkan tiga inikator sebagai acuannya yaitu tingkat harapan hidup, tingkat melek huruf, dan pendapatan riil per kapita berdasarkan paritas daya beli.

4. Untuk mengevaluasipembangunan dibidang pendidikan digunakan tingkat partisipasi pendidikan (TPP) yaitu Angka Partisipasi Murni (APM) dan Angka Partisipasi Kasar (APK).

5. Untuk mengevaluasi keberhasilan pembangunan dibidang sumberdaya manusia digunakan indikator tingkat partisipasi angkatan kerja (TPAK) 
8| Wahidin, Sahri, Putu Karismawan, M.Firmansyah /Analisis Kinerja.....

dengan rumus $(\mathrm{Hg}$. Suseno Triyanto

Widodo, 1990):

$$
\begin{gathered}
\text { AK } \\
\text { TPAK = ------- . } 100 \% \\
\text { PUK }
\end{gathered}
$$

Keterangan :

AK = Angkatan Kerja, yaitu penduduk dalam usia kerja yang sudah bekerja

PUK = Penduduk Usia Kerja

\section{HASIL PENELITIAN DAN PEMBAHASAN}

Hasil Pembangunan Dalam Aspek

\section{Kesejahteraan Ekonomi Penduduk}

Tabel.1 PDRB per Kapita ADH Konstan 2010 dan ADH Berlaku.

\begin{tabular}{|c|c|c|c|c|}
\hline Tahun & $\begin{array}{c}\text { PDRB Per Kapita } \\
\text { Adh Konstan Th. 2010 }\end{array}$ & $\begin{array}{c}\% \\
\text { Kenaikan }\end{array}$ & $\begin{array}{c}\text { PDRB Per Kapita } \\
\text { Adh Berlaku }\end{array}$ & $\begin{array}{c}\% \\
\text { Kenaikan }\end{array}$ \\
\hline 2011 & $14,705,765$ & - & $14,879,834$ & - \\
\hline 2012 & $14,276,688$ & $-2,91$ & $14,853,735$ & $-0,53$ \\
\hline 2013 & $15,067,422$ & 5,53 & $15,899,369$ & 7,03 \\
\hline 2014 & $15,369,944$ & 2,01 & $17,097,660$ & 7,53 \\
\hline 2015 & $18,479,397$ & 20,23 & $21,479,397$ & 25,62 \\
\hline 2016 & $19,310,678$ & 4,49 & $23,742,420$ & 10,53 \\
\hline Rata-rata & 16.500 .825 & 8,06 & 18.614 .516 & 12.67 \\
\hline
\end{tabular}

Sumber: NTB Dalam Angka dan Statistik Indonesia Dalam Angka, diolah

Bagan 1 PDRB Per Kapita AD Konstan 2010 dan ADH Berlaku

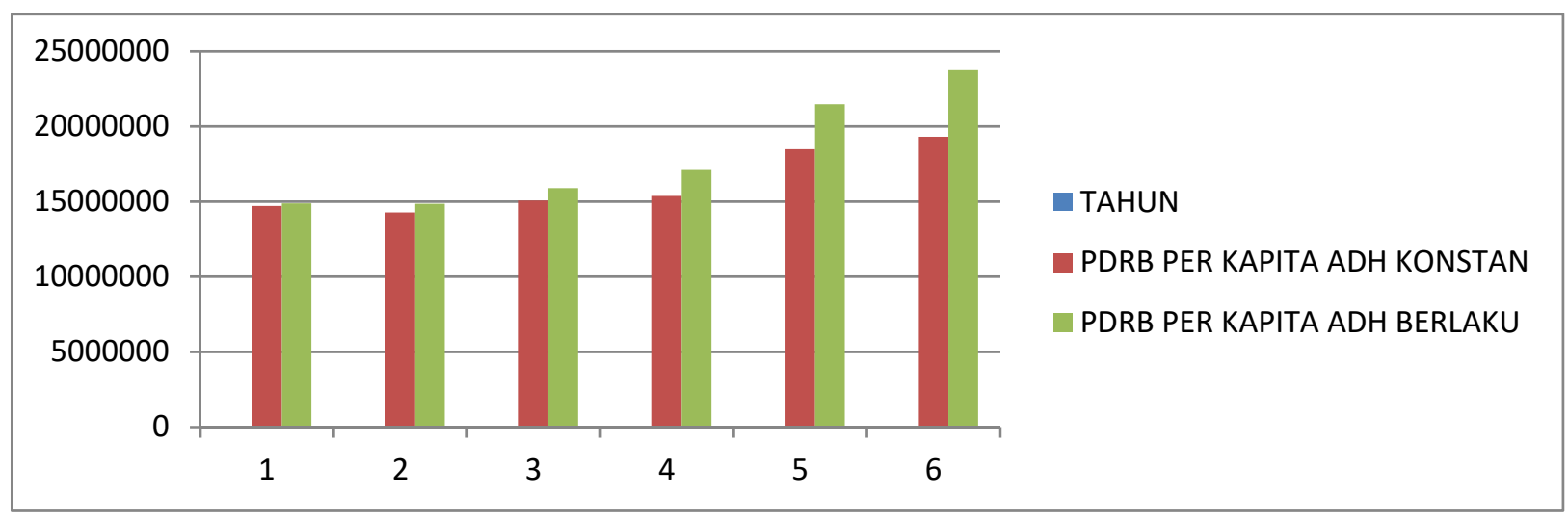

Sumber : NTB Dalam Angka dan Statistik Indonesia Dalam Angka, diolah
PDRB Per Kapita sebagai indikator kesejahteraan ekonomi penduduk NTB selama tahun 2011 - 2016 mengalami kenaikan. Hal ini mengindikasikan kesejahteraan ekonomi penduduk NTB mengalami kenaikan. Tahun 2011, PDRB per kapita harga berlaku sebesar Rp. 14.879.834, naik menjadi Rp. 15.899.369 tahun 2013 dan naik lagi menjadi Rp. 23.742.420. Untuk lebih jelasnya mengenai PDRB per Kapita Propinsi dapat dilihat pada tabel 1 dan bagan 1.dibawah ini. 
Kesejahteraan ekonomi penduduk NTB per kapita lebih besar dari kebutuhan fisik semakin baik juga ditunjukkan oleh PDRB minimum (KFM).

Tabel 2. Rata-rata PDRB Per Kapita Per Bulan dan Kebutuhan Fisik Minimum Sebulan Propinsi NTB.

\begin{tabular}{|c|c|c|}
\hline Tahun & $\begin{array}{c}\text { Rata-rata PDRB Per Kapita Per Bulan } \\
(\text { Rp) }\end{array}$ & $\begin{array}{c}\text { Kebutuhan Fisik Minimum (KFM) } \\
\text { sebulan (Rp) }\end{array}$ \\
\hline 2011 & 1.239 .990 & 1.007 .000 \\
\hline 2012 & 1.237 .810 & 1.222 .088 \\
\hline 2013 & 1.302 .300 & 1.403 .700 \\
\hline 2014 & 1.424 .810 & 1.410 .294 \\
\hline 2015 & 1.789 .950 & 1.430 .064 \\
\hline 2016 & 1.978 .540 & 1.450 .111 \\
\hline
\end{tabular}

Sumber: Statistik Indonesia Dalam Angka dan NTB dalam angka, diolah.

Tingkat kesejahtraan ekonomi penduduk NTB hanya lebih tinggi sedikit dari kesejahteraan ekonomi penduduk NTT dan Maluku.Tetapi masih jauh lebih rendah dari kesejahteraan ekonomi penduduk propinsi-propinsi lainnya di Indonesia.Lebih jelasnya dapat dilihat pada tabel 3 berikut ini.

Tabel 3. Rata-rata PDRB Per Kapita Beberapa Propinsi Atas Dasar Harga Berlaku Selama Tahun 2011 - 2016 ( Rp. Ribu)

\begin{tabular}{|l|c|}
\hline \multicolumn{1}{|c|}{ Propinsi } & Rata-rata PDRB Per Kapita Per Tahun \\
\hline Bali & 36.048 .11 \\
\hline Nusa Tenggara Barat & $17,946.77$ \\
\hline Nusa Tenggara Timur & $13,083.10$ \\
\hline Kalimantan Barat & $27,074.27$ \\
\hline Kalimantan Selatan & $31,327.71$ \\
\hline Sulawesi Utara & $32,543.48$ \\
\hline Sulawesi Selatan & $33,726.64$ \\
\hline Sulawesi Tenggara & $31,128.67$ \\
\hline Gorontalo & $21,693.64$ \\
\hline Sulawesi Barat & $22,141.54$ \\
\hline Maluku & $17,864.04$ \\
\hline Papua & $43,719.24$ \\
\hline
\end{tabular}

Sumber: Statistik Indonesia dalam Angka, diolah.

\section{Hasil Pembangunan Dalam Aspek \\ Distribusi Pendapatan Antar Penduduk}

Ketimpangan distribusi pendapatan antar penduduk NTB masih tergolong sedang. Hal ini ditunjukkan oleh koefisien Gini ratio yang berada di bawah angka 0,5 baik penduduk perkotaan maupun penduduk pedesaan. Kondisi ketimpangan ini tidak berbeda jauh dengan kondisi ketimpangan distribusi pendapatan antar penduduk di propinsi 
10 | Wahidin, Sahri, Putu Karismawan, M.Firmansyah /Analisis Kinerja.....

Bali dan NTT.Lebih jelasnya dapat dilihat pada tabel 4 di bawah ini.

Tabel 4.Gini Rasio Perkotaan dan Pedesaan di Provinsi NTB, NTT dan Bali 2002-2016

\begin{tabular}{|l|c|c|c|c|c|c|}
\hline \multirow{2}{*}{ Tahun } & \multicolumn{3}{|c|}{ Perkotaan } & \multicolumn{3}{c|}{ Pedesaan } \\
\cline { 2 - 7 } & NTB & NTT & BALI & NTB & NTT & BALI \\
\hline $201 *^{*}$ & 0,444 & 0,347 & 0,370 & 0,328 & 0,345 & 0,313 \\
\hline $2011^{*}$ & 0,380 & 0,357 & 0,409 & 0,336 & 0,312 & 0,337 \\
\hline $2012^{*}$ & 0,390 & 0,379 & 0,459 & 0,291 & 0,289 & 0,342 \\
\hline $2013^{*}$ & 0,398 & 0,360 & 0,419 & 0,323 & 0,268 & 0,302 \\
\hline $2014^{*}$ & 0,426 & 0,345 & 0,429 & 0,307 & 0,279 & 0,315 \\
\hline $2015^{*}$ & 0,399 & 0,332 & 0,382 & 0,333 & 0,288 & 0,332 \\
\hline $2016^{*}$ & 0,391 & 0,330 & 0,369 & 0,317 & 0,281 & 0,329 \\
\hline
\end{tabular}

*Data per 1 Maret tahun ybs.

Sumber: www/BPS.go.id. diunduh tanggal 22-9-2017jam.06.28wita

\section{Hasil Pembangunan Dalam Aspek \\ Pembangunan Manusia}

Salah satu instrumen yang digunakan untuk mengukur kualitas modal manusia adalah dengan angka Indeks Pembangunan Manusia (IPM).

Pembangunan manusia memiliki tiga unsur penting yaitu, aspek pendidikan, kesehatan dan ekonomi (daya beli). Provinsi Nusa Tenggara Barat sejak tahun 2012 sampai dengan 2016 menempati posisi 30 dari 34 provinsi di Indonesia.
Pertumbuhan IPM NTB termasuk tertinggi di Indonesia, pada tahun 2010 nilai IPM NTB sekitar 61 tumbuh menjadi 65,81. Sungguh-pun mengalami pertumbuhan tertinggi, namun belum cukup mampu untuk meningkatkan angka IPM secara komulatif di atas posisi 30. Butuh upaya percepatan yang maksimal untuk mengejar ketertinggalan dari daerah lain. Gambaran perkembangan IPM NTB dari tahun 2010 sampai 2016 disajikan pada bagan di bawah ini.

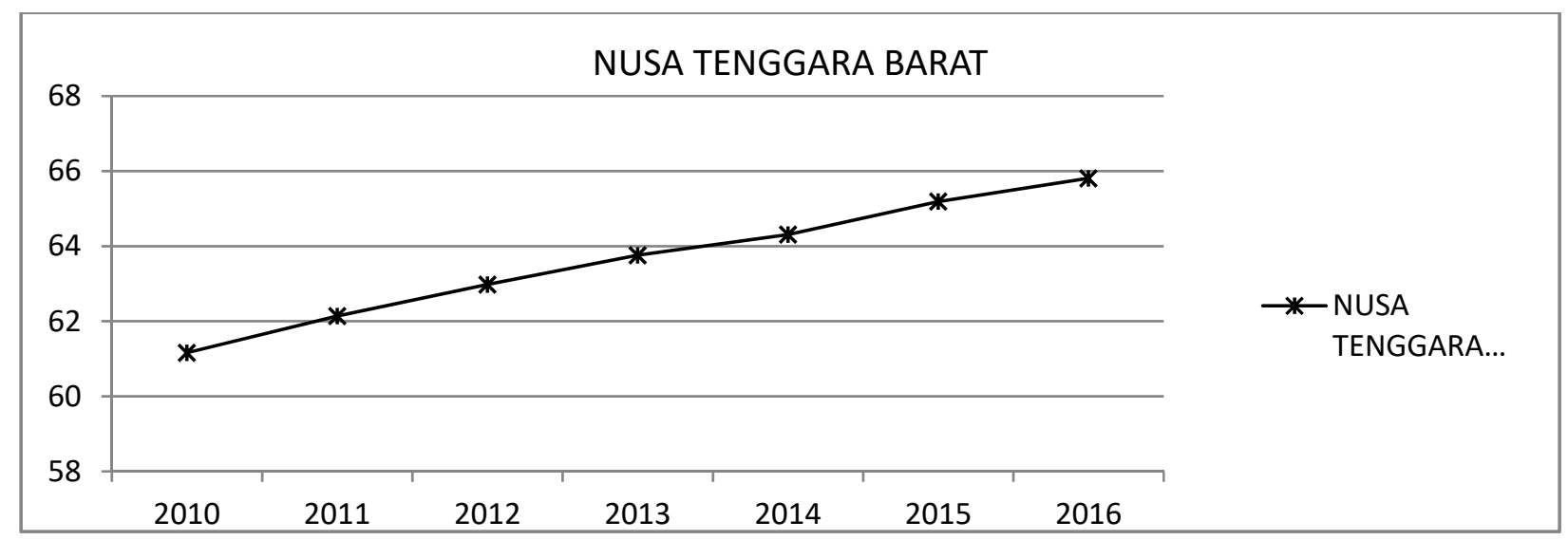


Bila dilihat perkabupaten dan kota di NTB dapat dijelaskan bahwa hanya dua kota di NTB yang nilai IPM di atas 70 , yaitu Kota
Mataram dengan nilai 77,2 dan Kota Bima dengan nilai 73,67. Nilai IPM 73 adalah setara dengan IPM Provinsi Bali.

Tabel 5. Nilai IPM kabupaten Kota se NTB

\begin{tabular}{|l|c|c|c|c|c|}
\hline \multirow{2}{*}{ Kabupaten/Kota } & \multicolumn{5}{|c|}{ Nilai IPM } \\
\cline { 2 - 6 } & $\mathbf{2 0 1 2}$ & $\mathbf{2 0 1 3}$ & $\mathbf{2 0 1 4}$ & $\mathbf{2 0 1 5}$ & $\mathbf{2 0 1 6}$ \\
\hline Lombok Barat & 62.24 & 62.91 & 63.52 & 64.62 & 65.55 \\
\hline Lombok Tengah & 60.57 & 61.25 & 61.88 & 62.74 & 63.22 \\
\hline Lombok Timur & 60.73 & 61.43 & 62.07 & 62.83 & 63.7 \\
\hline Sumbawa & 61.96 & 62.44 & 62.88 & 63.91 & 64.89 \\
\hline Dompu & 62.6 & 63.16 & 63.53 & 64.56 & 65.48 \\
\hline Bima & 61.05 & 62.08 & 62.61 & 63.48 & 64.15 \\
\hline Sumbawa Barat & 66.45 & 66.86 & 67.19 & 68.38 & 69.26 \\
\hline Lombok Utara & 58.19 & 59.2 & 60.17 & 61.15 & 62.24 \\
\hline Kota Mataram & 74.22 & 75.22 & 75.93 & 76.37 & 77.2 \\
\hline Kota Bima & 71.21 & 71.72 & 72.23 & 72.99 & 73.67 \\
\hline Nusa Tenggara Barat & $\mathbf{6 2 , 9 8}$ & $\mathbf{6 3 , 7 6}$ & $\mathbf{6 4 , 3 1}$ & $\mathbf{6 5 , 1 9}$ & $\mathbf{6 5 , 8 1}$ \\
\hline
\end{tabular}

Sumber: Data BPS NTB

\section{Hasil Pembangunan Dalam Aspek Partisipasi Pendidikan}

Untuk mengetahui seberapa banyak penduduk yang memanfaatkan fasilitas pendidikan dapat dilihat dari persentase penduduk menurut partisipasi sekolah. Partisipasi pendidikan secara umum dapat diamati melalui: Angka Partisipasi Sekolah (APS), Angka Partisipasi Kasar (APK), serta Angka Partisipasi Murni (APM).

Angka Partisipasi Sekolah (APS) merupakan ukuran daya serap lembaga pendidikan terhadap penduduk usia sekolah. APS menggambarkan sejauh mana penduduk usia sekolah memanfaatkan fasilitas pendidikan. Tingginya angka APS menunjukkan semakin besar masyarakat yang berkesempatan untuk menikmati pendidikan.

Berdasar data BPS, APS NTB dalam lima tahun terakhir selalu lebih tinggi dari ratarata nasional. Hal ini menunjukkan bahwa tingkat partisipasi sekolah masyarakat NTB relatif baik. Data APS NTB dan nasional disajikan pada bagan di bawah ini. 
Tabel. Perbandingan Tingkat Partisipasi Sekolah NTBdan Indonesia

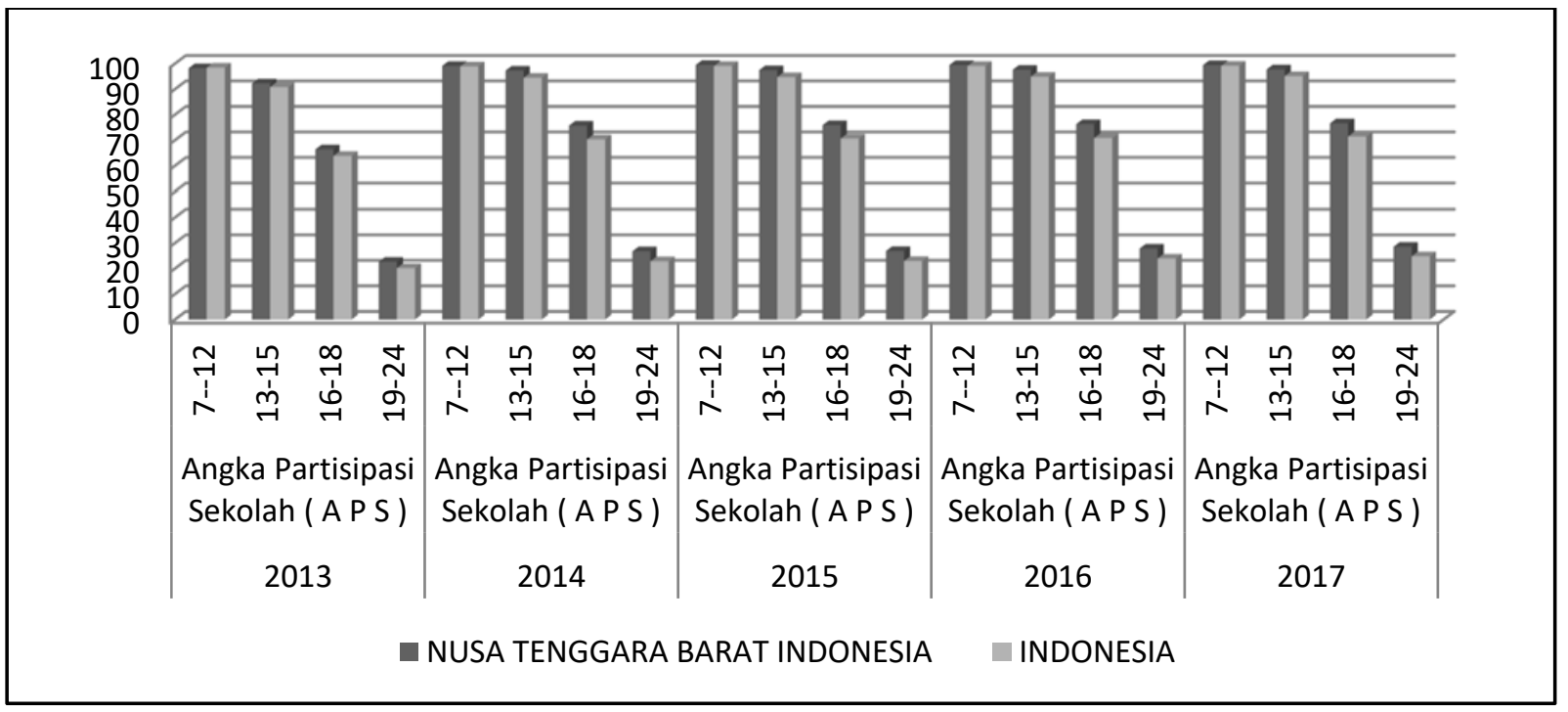

Sumber: Data BPS, 2017

Bila dilihat berdasar umur, partisipasi sekolah rentang umur 7-12 tahun (SD) lebih tinggi dibandingkan dengan tingkat umur di atasnya (SMP ke atas). Umur 19-24 tahun merupakan umur produktif bagi penduduk, sehingga aktifitas penduduk terbagi kedalam aktifitas sekolah dan bekerja. Rendahnya partisipasi sekolah umur produktif diakibatkan oleh aktifitas lain selain bersekolah bagi sebagian penduduk. Sungguh-pun demikian, terjadi peningkatan dari tahun 2013 sampai dengan 2017, yaitu kurang dari 30 persen menjadi di atas 30 persen. Hal ini menunjukkan bahwa kemampuan dan keinginan untuk melanjutkan pendidikan menjadi lebih tinggi bagi usia produktif di NTB.

Untuk menunjukkan tingkat partisipasi penduduk secara umum pada suatu tingkat pendidikan disebut sebagai Angka Partisipasi Kasar (APK). Bila diamati perbandingan APK antara NTB dengan Indonesia selama lima tahun terakhir, menunjukan bahwa nilai APK NTB relative lebih tinggi dari pada rata-rata nasional. Hal ini menunjukan tingkat partisipasi masyarakat NTB terhadap pendidikan secara umum juga relative baik. Untuk mengamati perbedaan itu, tersaji pada bagan di bawah ini 
Tabel. Perbandingan Antara APK Indonesia Dengan NTB

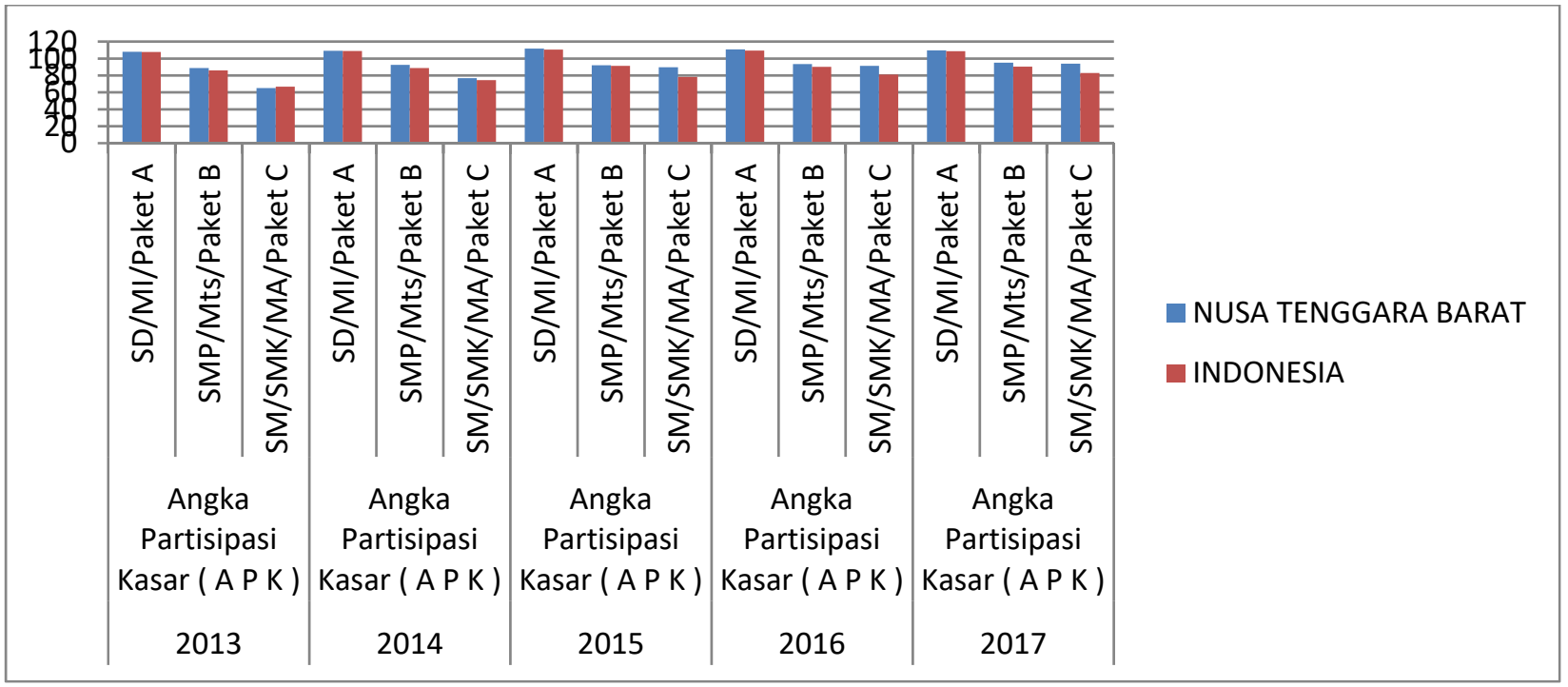

Sumber: BPS, 2017

Dari data ini menunjukkan bahwa kesadaran dan partisipasi pendidikan tingkat remaja semakin baik. Semoga tingginya partisipasi kasar pendidikan sekolah menengah atas ini diikuti dengan tingginya siswa yang melanjutkan ke jenjang perguruan tinggi.
APK yang tinggi menunjukkan tingginya tingkat partisipasi sekolah, tanpa memperhatikan ketepatan usia sekolah pada jenjang pendidikannya. Nilai APK (lebih dari 100 persen) tinggi menjelaskan bahwa daerah itu mampu menampung penduduk usia sekolah melebihi dari target.

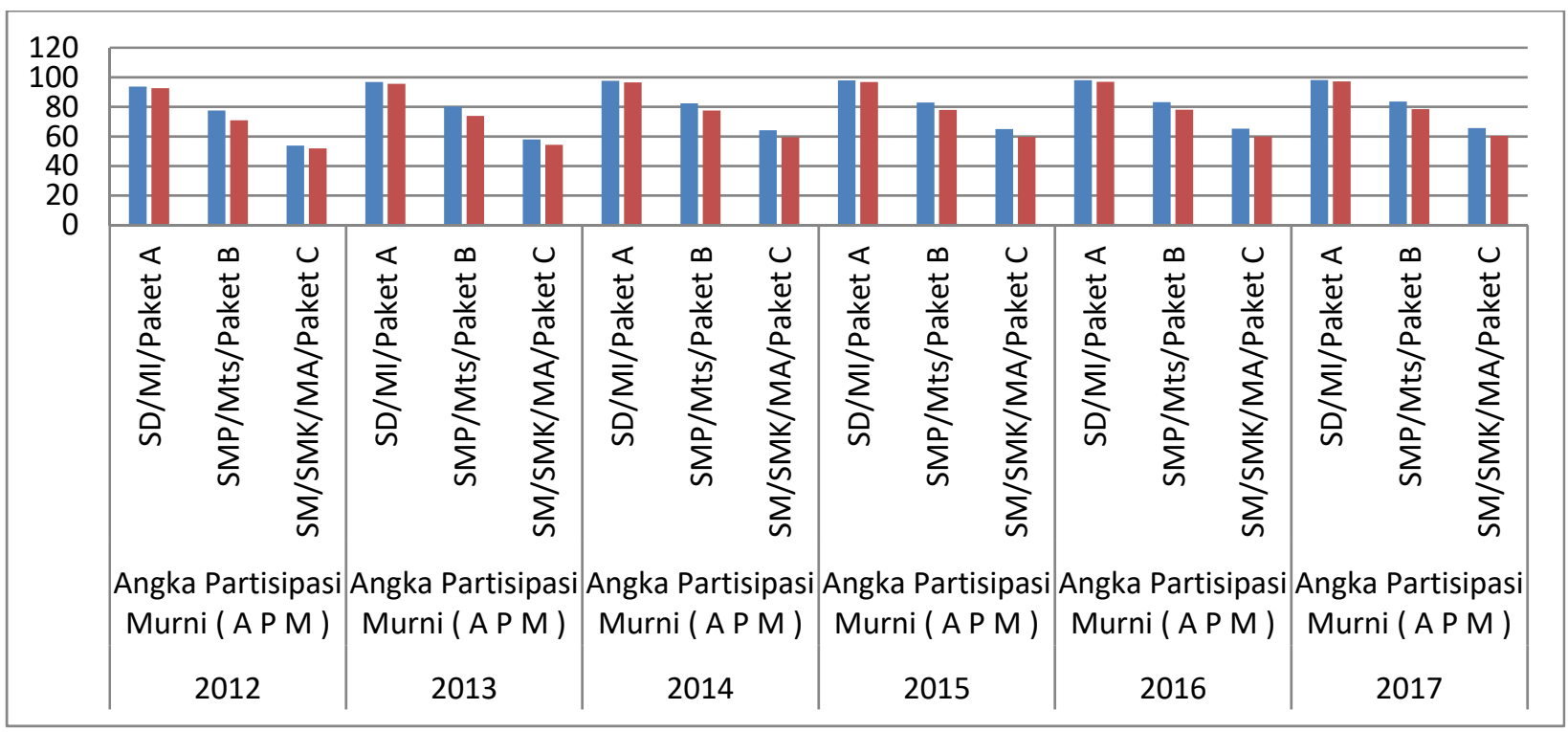


Angka partisipasi murni (APM) di NTB bahkan di Indonesia belum sampai di atas $100 \%$ artinya tidak ada daerah menampung penduduk usia sekolah melebihi target. Namun demikian, APM tingkat SMA sederajat tumbuh hampir 100 persen dari tahun 2013 sampai dengan tahun 2017. Demikian pula dengn level SMP dan SMA sederajat juga mengalami pertumbuhan yang relatif baik.

Dengan demikian, mengamati indikator pendidikan di NTB secara umum dapat disimpulkan bahwa terjadi progres yang baik. Masyarakat NTB semakin baik dalam berpartisipasi terhadap pendidikan, artinya masyarakat semakin merasakan pentingnya untuk bersekolah dalam mencapai kehidupan yang lebih baik ke depannya.

\section{Hasil Pembangunan Dalam Aspek Partisipasi Kerja}

Angka Tingkat Partisipasi Angkatan Kerja (TPAK) adalah indikator untuk mengukur kondisi ketenagakerjaan suatu wilayah. Dengan kata lain, TPAK memberi gambaran seberapa besar keterlibatan penduduk dalam kegiatan perekonomian (BPS, 2017). Nilai TPAK NTB dalam lima tahun terakhir tersaji pada bagan di bawah ini:

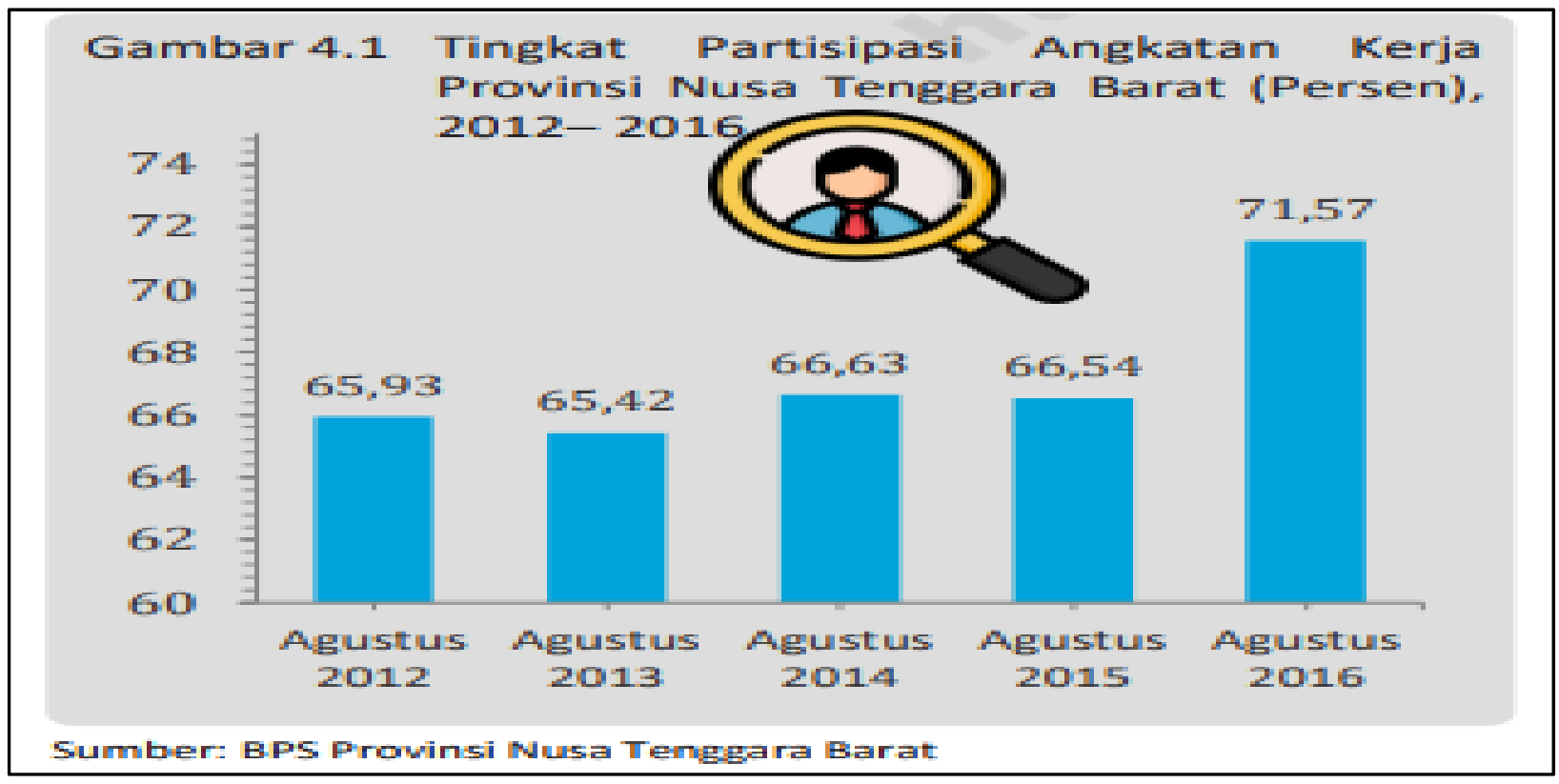

Trend nilai TPAK NTB dari tahun ke tahun mengalami peningkatan, walau secara nominal mengalami fluktuasi, tergantung dari kondisi perekonomian NTB. Peningkatan paling ekstrim terjadi pada tahun 2016 terhadap 2015, peningkatan TPAK meningkat drastis dari 66,54 menjadi 71,57 . 


\section{KESIMPULAN DAN SARAN}

\section{Kesimpulan}

1. Pembangunan ekonomi propinsiNusa Tenggara Barat (NTB) dalam lima tahun terakhir ini telah meningkatkan kesejahteraan ekonomi penduduk. Kesejahteraan ekonomi penduduk NTB meningkat dari tahun ke tahun. Tetapi tingkat kesejahteraan ekonomi penduduk NTB masih lebih rendah dari tingkat kesejahteraan ekonomi penduduk propinsi-propinsi lain di Indonesia..

2. Distribusi pendapatan antar penduduk NTB dalam lima tahun terakhir ini masih dalam ketimpangan sedang. Ketimpangan sedang ini, terjadi baik di daerah perkotaan maupun di daerah pedesaan. Ketimpangan distribusi pendapatan antar penduduk propinsi NTB tidak jauh beda dengan ketimpangan distribusi pendapatan antar peduduk di propinsi Bali dan Nusa Tenggara Timur (NTT).

3. Pembangunan manusia propinsi NTB berada pada urutan ke 30 dari 34 propinsi di Indonesia. Pertumbuhan IPM NTB termasuk tertinggi di Indonesia, namun belum cukup mampu untuk meningkatkan angka IPM secara komulatif di atas posisi 30.Butuh upaya percepatan yang maksimal untuk mengejar ketertinggalan dari daerah lain.

4. Tingkat partisipasi pendidikan masyarakat Nusa Tenggara Barat relatif lebih baik. Angka partisipasi sekolah (APS) dan Angka partisipasi kasar (APK) NTB lebih tinggi dari rata-rata nasional. Angka partisipasi murni (APM) NTB sudah melebihi angka sembilan puluh persen. Masyarakat NTB semakin baik dalam berpartisipasi terhadap pendidikan.

5. Tingkat partisipasi angkatan kerja penduduk NTB dari tahun ke tahun mengalami peningkatan. Peningkatan paling ekstrim terjadi pada tahun 2016 terhadap 2015, peningkatan TPAK meningkat drastis dari 66,54 menjadi 71,57. Sektor perdagangan dan sektor manufaktur memberi pengaruh terhadap peningkatan TPAK di Provinsi Nusa Tenggara Barat.

Saran.

1. Untuk lebih meningkatkan kesejahteraan ekonomi penduduk, disarankan kepada pemerintah propinsi NTB untuk menciptakan iklim usaha yang kondusif agar kegiatan investasi semakin meningkat. Kegiatan investasi meningkatkan maka laju pertumbuhan ekonomi daerah meningkat dan 
16 | Wahidin, Sahri, Putu Karismawan, M.Firmansyah /Analisis Kinerja.....

kesejahteraan ekonomi masyarakat semakin meningkat pula.

2. Walapun tingkat ketimpangan pendapatan antar penduduk NTB tergolong tingkat sedang, namun harus diusahakan berbagai kebijakan daerah agar ketimpangan pendapatan ke tingkat yang rendah. Kebijakankebijakan untuk meningkatkan kesempatan kerja penduduk terutama pada usaha kecil dan menengah (UKM) dan pembangunan pertanian harus ditingkatkan.

3. Upaya besar harus terus dilakukan dalam bidang kesehatan, pendidikan, dan ekonomi untuk meningkatkan angka harapan hidup, menurunkan jumlah penduduk melek huruf, dan meningkatkan pembangunan ekonomi.

4. Peningkatan sarana dan prasarana harus terus dilakukan oleh pemerintah daerah NTB agar partisipasi masyarakat dalam pendidikan semakin meningkat.

5. Perluasan lapangan kerja harus terus diupaya terutama dalam usaha kecil dan menengah yang terbukti banyak menyerap tenaga kerja.

\section{DAFTAR PUSTAKA}

Arsyad Lincolind, Ekonomi Pembangunan, Sekolah Tinggi Ilmu Ekonomi YKPN, Yogyakarta, 2004.

Arsyad, L. 2010. Pengantar Perencanaan dan Pembangunan Daerah. Edisi Pertama, Yogyakarta, BPFE

Badan Pusat Statistik. Nusa Tenggara Barat Dalam Angka Tahun 2012 . Nusa Tenggara Barat Dalam Angka Tahun 2014 . Nusa Tenggara Barat Dalam Angka Tahun 2016

Bali Bisnis.Com.diunduh tanggal 21-9-2017.

Dendi Asita, dkk. Perencanaan Strategi Partisipatif Pengembangan Ekonomi Lokal Dalam Bingakai Ekonomi Kerakyatan. P2k Unram. 2010..

Irwan dan M. Suparmoko, 1988. Ekonomi Pembangunan.

Jhingan, M.L, 2010. Ekonomi Pembangunan Dan Perencanaan. Ed. Ke 13. Jakarta, PT. Raja Grafindo Persada.

Kuncoro, M.; 2010.Dasar-Dasar Ekonomika Pembangunan. Edisi 5, Yogyakarta, UPP STIM YKPN. 
Nazir, Moh, 2011. Metode Penelitian, Ed. Ke 7, Bogor, Ghalia Indonesia.

Nehen, Ketut, Perekonomian Indonesia, Udayana University Press, Denpasar, 2012.

Nurmayanti, Dian Anggraini, Distribusi Pendapatan dan Kemiskinan di Indonesia, diananggraini.blogspot.com.2013/05. diunduh tanggal 21 September 2017.

Sukirno, Sadono, 2013. Ekonomi Pembangunan. Proses, Masalah Dan Dasar Kebijakan. Edisi Kedua. Jakarta, Kencana Pranada Media Group.

Todaro, Michael P. 2011. Pembangunan Ekonomi. Ed. Ke - 11. Jakarta: Erlangga

Widodo, Tri, 2006. Perencanaan Pembangunan. Cetakan Pertama, UPP STIM YKPN Yogyakarta.

Widodo, Hg. Suseno Triyanto, 1990. Indikator Ekonomi. Yogyakarta, Kanisius.

www. Bps.go.id/link/ginirasio provinsi 2002-2007 